\title{
ASTHMA
}

\section{Association of CCR5 $\Delta 32$ with reduced risk of childhood but not adult asthma}

\author{
P Srivastava, P J Helms, D Stewart, M Main, G Russell
}

Thorax 2003;58:222-226

See end of article for authors' affiliations

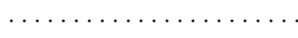

Correspondence to: Professor P J Helms, Department of Child Health, University of Aberdeen, Aberdeen AB25 2ZD, UK p.j.helms@abdn.ac.uk

Revised version received 25 September 2002 Accepted for publication 26 October 2002
Background: A number of potential candidate genes have been implicated in the pathogenesis of asthma. A 32 base pair deletion in the CCR5 gene renders this chemokine receptor non-functioning and has been shown to be associated with a reduced prevalence of asthma in childhood. The mechanism may be related to impairment of pathogen entry into cells and modified host inflammatory response. We sought to determine the influence of the CCR5 $\Delta 32$ mutation on asthma and allergy in the transition from childhood to adulthood.

Methods: 627 individuals first studied as part of a whole population schoolchildren cohort in 1989 when aged 8-12 years were followed up 10 years later for respiratory and allergy symptoms and laboratory markers of atopy. CCR5 32 status was also characterised and the association with childhood and adulthood symptoms determined.

Results: The follow up sample was representative of the original cohort except for a slightly greater prevalence of symptomatic individuals. As children, none who were homozygous for the CCR5 332 mutation had a current physician's diagnosis of asthma. In multivariate analysis and controlling for known confounders, the protective effect of carrying the allele in childhood was highly significant (OR $0.31,95 \% \mathrm{Cl} 0.14$ to $0.72, \mathrm{p}=0.006$ ). There was no protective association with "current asthma" as classified in adulthood within the same population. Subjective or laboratory markers of atopy in childhood or adulthood were not associated with the CCR5 32 mutation. Methacholine bronchial hyperresponsiveness in adulthood was also unrelated to gene carrier status.

Conclusions: In a population with a high allelic frequency for the CCR5 32 mutation, a significant protection against childhood asthma is evident which is independent of atopy. This protection is lost in the transition between childhood and early adulthood. The contribution of different genetic candidates to the expression of asthma may change with advancing maturity and confound the interpretation of association and linkage studies unless age is taken into account.

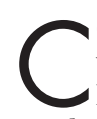
CR5 is a specific chemokine receptor expressed on a variety of cells including $\mathrm{T}$ helper 1 (but not T helper 2) lymphocytes. ${ }^{1}$ A 32 base pair deletion (CCR5 32 ) results in a receptor that is not expressed on the cell surface. From observations of low HIV-1 prevalence in carriers of this variant $^{2}$ it has been postulated that the CCR5 332 polymorphism may have a wider disease modifying role related to inhibition of pathogen entry into cells..$^{3-5}$ Further support for the role of the natural receptor in inflammation comes from the observation that significantly increased levels of the CCR5 ligand RANTES (which recruits monocytes, $\mathrm{T}$ cells, and eosinophils) are found in bronchial lavage samples from patients with asthma. ${ }^{67}$ Neutralisation of RANTES in mice following allergen challenge has been shown to reduce airway hyperresponsiveness, ${ }^{8}$ and mice lacking CCR5 exhibit diminished airway hyperresponsiveness to methacholine together with reduced levels of inflammatory cells and mediators. These observations lend further support to a role for the receptor in modulating airway inflammatory responses and associated bronchial responsiveness.

We have previously reported that children aged 5-15 years who carried the CCR5 $\Delta 32$ polymorphism were protected against the development of asthma and that no asthma was recorded in children homozygous for the mutation. ${ }^{9}$ This observation suggested that the allele might determine the amount of functioning receptor and associated responses to infective agents through a "dose dependent" effect. However, Mitchell et al were unable to replicate the association in an older population of children, adolescents, and young adults and argued that an abnormally truncated and non-functioning receptor might be expected to direct immune responses towards a Th2 profile, thus increasing the likelihood of atopic disease. ${ }^{10}$ They also suggested that differences in genetic background and environment could explain this failure of replication as there appears to be a north to south European gradient for prevalence of the CCR5 532 polymorphism, ranging from $16 \%$ in Scandinavia to $4 \%$ in Sardinia (mean European frequency 9\%). ${ }^{11}$ Iyer et al have also demonstrated segregation of the polymorphism according to race with frequencies of $3.57 \%$ noted in white Americans, $1.55 \%$ in the African American population, and a complete absence of the mutant allele in Asian Americans and Native Americans. ${ }^{12}$

From the few longitudinal studies that have followed the natural history of asthma and wheezing illness it is apparent that many children, particularly those with mild symptoms and predominantly viral associated episodes, become asymptomatic in the transition to adult life. ${ }^{13}{ }^{14}$ Whereas atopy and non-specific bronchial hyperresponsiveness (BHR) may be risk factors for the persistence of asthma into adulthood ${ }^{15}$ and viral associated wheeze of childhood has a favourable long term outcome, ${ }^{13}{ }^{14}$ we are unaware of any reports that have examined the association of candidate genes with asthma and wheezing illness during the transition from childhood to adult life. We therefore sought to confirm or refute our previous observations on the association of CCR $5 \Delta 32$ with childhood asthma in our population and to test the hypothesis that the contribution of this particular candidate diminishes in the transition from childhood to early adulthood.

\section{METHODS}

If CCR5 $\Delta 32$ is associated with the expression of childhood asthma but not with adult asthma, this could be investigated 
using a number of different designs including whole population, case control or cohort studies, all spanning the age distribution from childhood to adulthood. However, in a population over an extended age range and studied at a single time point it would be difficult to account for the "epoch effect" due to the increase in incidence of asthma and atopy that has occurred over the past three decades. ${ }^{16-18}$ We therefore sought to address this issue by studying the association of CCR5 532 polymorphism in a sample drawn from a whole population followed from childhood into early adulthood.

\section{Study population}

After obtaining approval from the Grampian research ethics committee, letters were sent to all 2082 young adults who could be traced and who had taken part in a 1989 survey $(n=3406)$ of Aberdeen primary schools when aged 8-12 years. ${ }^{16}$ Of those traced, attempts to contact them by telephone and letter were successful in 1407 cases in whom screening data were obtained by telephone questionnaire. Of this traced population, 711 attended the study centre during the year 1999-2000 when aged 18-22 years. From this subset of the original 1989 population, follow up data were obtained by an interviewer administered questionnaire based on the European Community Respiratory Health Survey (ECRHS) ${ }^{19}$ and the American Thoracic Society (ATS) questionnaires. ${ }^{20}$ In order to maintain consistency with data obtained from the original cohort, additional questions as used in 1989 were also included. The cohort was studied as if it were two independent whole population samples of children and adults in order to assess any association of CCR $5 \Delta 32$ with asthma in the two age classifications (8-12 and 18-22 years). "Current asthma in childhood" was defined from the 1989 database as a physician's diagnosis of asthma ever plus current wheeze (wheeze within the last 3 years of the 1989 study). "Current asthma in adulthood" was defined as a physician's diagnosis of asthma ever and current wheeze (wheeze within the last 12 months of the 1999/2000 study) - see discussion for explanation of why two different definitions of current wheeze were used and how these relate to each other. In the current study "childhood only wheeze" was defined as current wheeze reported in the 1989 survey but no longer present in the 1999/ 2000 study, "adult onset wheeze" was defined as current wheeze in 1999/2000 but not in 1989, and "persistent wheeze" was defined as being present on both occasions. A fourth group consisted of those who had "never wheezed" with no reported symptoms on either study occasion.

In the original 1989 study "current" atopy status was based on questionnaire responses for the presence of hayfever and/or eczema within the last 12 months. ${ }^{16}$ In order to maintain consistency, "current atopy" in 1999/2000 was defined as a history of eczema and/or hayfever within the last 12 months of the 1999/2000 study.

\section{Laboratory measures}

In the 1999/2000 study asthma and atopy associated phenotypes were further characterised. The Cockroft protocol was used to determine BHR to methacholine (Sigma Aldrich, Dorset, UK ) and results documented as the concentration of methacholine required to reduce the forced expiratory volume in 1 second $\left(\mathrm{FEV}_{1}\right)$ by $20 \%\left(\mathrm{PC}_{20}\right),{ }^{21}$ with a positive result considered to be a concentration of $\leqslant 8 \mathrm{mg} / \mathrm{ml}$. Results were expressed as both categorical and continuous variables for the purposes of analysis. Atopy was assessed by measurement of RAST, total serum IgE (Pharmacia and Upjohn Diagnostics, Milton Keynes, UK), and skin prick testing to a panel of 14 common inhaled allergens (ALK, Reading, UK). Positive values were taken as $\geqslant 1$ RAST, $\geqslant 120 \mathrm{IU}$, and $\geqslant 3 \mathrm{~mm}$, respectively, and a grouping variable (any one measure of atopy positive) was derived. DNA was extracted from whole blood and CCR5 genotype-WT/WT (wild type), WT/32 (heterozygous) or $32 / 32$ (homozygous) - and determined by PCR (primers from MWG Biotech Limited, UK). ${ }^{\text {? }}$

\section{Data analysis}

Data analysis was carried out using SPSS version 9.0 (SPSS Inc, Chicago, IL, USA); $t$ tests, $\chi^{2}$ tests, and multivariate logistic regression models were used to assess the relationships between recorded variables.

\section{RESULTS}

\section{Demographic data}

There is no population stratification in this cohort which was in Hardy Weinberg equilibrium.

Table 1 shows the demographic breakdown at each stage of population selection. The 2082 individuals traced were representative of the original 1989 whole population sample in terms of sex, social class, ${ }^{22}$ and symptoms with no significant differences in any of these variables. The sample of individuals who consented for full assessment and who attended in 1999-2000 $(\mathrm{n}=711)$ comprised a greater proportion of symptomatic individuals as defined in the original 1989 cohort. Significant differences were noted for "ever asthma" $(p=0.04)$, "ever eczema" $(p=0.008)$, and "wheeze within the last 3 years" $(p=0.015)$. Significantly fewer of this group were exposed to smoke during childhood $(p=0.0001)$. Results from non-responders/repeated non-attenders/those declining to proceed are not shown but can be summarised as follows: there were no significant demographic differences between those declining to proceed $(n=480)$ and either the 1989 population or those 927 who agreed to take part at first

Table 1 Population characteristics (based on 1989 data)

\begin{tabular}{|c|c|c|c|c|c|c|}
\hline $\begin{array}{l}\text { Variables categorised in } \\
1989\end{array}$ & $\begin{array}{l}1989 \\
(n=3406)\end{array}$ & $\begin{array}{l}\text { Traced in } \\
1999 \\
(n=2082)\end{array}$ & $\begin{array}{l}\text { Replied in } \\
1999 \\
(n=1407)\end{array}$ & $\begin{array}{l}\text { Agreed to } \\
\text { proceed } \\
(n=927)\end{array}$ & $\begin{array}{l}\text { Attended } \\
(n=711)\end{array}$ & $\begin{array}{l}\text { Complete phenotype } \\
\text { and genotype data } \\
\text { ( } n=627)\end{array}$ \\
\hline Ever asthma & 10.1 & 11.0 & 11.2 & 11.4 & 13.1 & 12.3 \\
\hline Ever breathless & 10.0 & 10.0 & 9.9 & 10.6 & 12.2 & 12.0 \\
\hline Ever persistent night cough & 13.9 & 13.4 & 13.6 & 14.3 & 15.2 & 14.5 \\
\hline Ever eczema & 12.0 & 13.0 & 13.5 & 14.5 & 15.9 & 16.1 \\
\hline Ever hayfever & 11.9 & 12.6 & 13.3 & 12.8 & 13.8 & 14.0 \\
\hline \multicolumn{7}{|l|}{ Occupation* } \\
\hline $1-3$ & 68.6 & 72.8 & 76.0 & 75.2 & 77.5 & 78.7 \\
\hline $4-9$ & 31.4 & 27.2 & 24.0 & 24.8 & 23.5 & 21.3 \\
\hline Male & 51.7 & 53.3 & 52.1 & 51.7 & 51.6 & 51.2 \\
\hline Female & 48.3 & 46.7 & 47.9 & 48.3 & 48.4 & 48.8 \\
\hline Wheeze in last 3 years & 19.8 & 20.1 & 21.2 & 21.6 & 24.1 & 23.9 \\
\hline Smokers in house (1999) & 57.9 & 55.7 & 54.5 & 53.9 & 50.4 & 49.5 \\
\hline
\end{tabular}


Table 2 Genotype and asthma status ( $n=627)$

\begin{tabular}{lllll}
\hline Status & WT/WT & WT/32 & $32 / 32$ & Total \\
\hline Current asthma in childhood & $70(90.9 \%)$ & $7(9.1 \%)$ & $0(0 \%)$ & 77 \\
Current asthma in adulthood & $95(81.2 \%)$ & $20(17.1 \%)$ & $2(1.7 \%)$ & 117 \\
Asymptomatic in childhood & $431(78.4 \%)$ & $112(20.4 \%)$ & $7(1.3 \%)$ & 550 \\
Asymptomatic in adulthood & $406(79.6 \%)$ & $99(19.4 \%)$ & $5(1.0 \%)$ & 510 \\
Whole population & $501(79.9 \%)$ & $119(19.0 \%)$ & $7(1.1 \%)$ & 627 \\
\hline
\end{tabular}

Table 3 Proportions of genotype by wheezing subgroups

\begin{tabular}{llll}
\hline $\begin{array}{l}\text { Wheezing } \\
\text { subgroups }\end{array}$ & WT/WT & WT/32 or 32/32 & Total \\
\hline Never (controls) & $259(75.3 \%)$ & $82(23.8 \%)$ & 344 \\
Childhood only & $53(93.0 \%)$ & $4(7.0 \%)$ & 57 \\
Adult onset & $114(84.4 \%)$ & $21(15.6 \%)$ & 135 \\
Persistent & $75(82.4 \%)$ & $16(17.6 \%)$ & 91 \\
Total & 501 & 126 & 627 \\
\hline
\end{tabular}

contact. Those with fewer symptoms were more likely to fail to attend at initial or rescheduled appointments $(n=216)$ and the differences were significant for "ever asthma" $(p=0.001)$, "ever breathless" $(p=0.001)$, "ever eczema" $(p=0.013)$, and "wheeze within the last 3 years" $(p=0.0001)$ compared with the 711 individuals who attended. The likelihood of being exposed to tobacco smoke during childhood was also greater in this group $(\mathrm{p}=0.001)$.

Mean age at follow up was 20 years (range 18-22). Males constituted $51.2 \%(\mathrm{n}=321)$ and females $48.8 \% \quad(\mathrm{n}=306)$; $52.8 \%(\mathrm{n}=331)$ had "ever wheezed", 27.0\% $(\mathrm{n}=169)$ had "ever asthma" according to the combined (and thus cumulative) responses from the 1989 survey and the 1999-2000 follow up questionnaire. The overall carrier frequency of CCR5 432 in the whole population was $19.0 \%$ (table 2 ).

\section{CCR5 $\Delta 32$}

Cross tabulation of frequencies (table 2) revealed that none of the CCR5 32 homozygous population had a current diagnosis of asthma in childhood and that the rates for heterozygotes were intermediate compared with the rates in those without the polymorphism, with a significant trend on $\chi^{2}$ analysis $\left(\chi^{2}\right.$ for trend 6.94, $\mathrm{p}=0.009$ ). With "current asthma in childhood" as the dependent variable in a logistic regression equation and correcting for current atopy (as reported in 1989) and sex, the protective effect of carrying the CCR $5 \Delta 32$ polymorphism was highly significant (OR $0.31,95 \%$ CI 0.14 to $0.72, p=0.006$ ).
However, in the same population characterised as having "current asthma" 10 years later there was no significant association with the CCR $5 \Delta 32$ variant on $\chi^{2}$ analysis $\left(\chi^{2}\right.$ for trend $0.023, \mathrm{p}=0.879$ ) or in the same logistic regression (OR $0.88,95 \%$ CI 0.52 to $1.48, p=0.627$ ). Current reported atopy in childhood and adulthood showed no association with CCR5 32 either in univariate or multivariate analyses. Objective measures of atopy (skin prick test, RAST, and IgE) and BHR (both measured in adulthood) also showed no association with CCR $5 \Delta 32$.

The frequency of the CCR5 $\Delta 32$ mutation showed a significant trend across the four wheezing subgroups (table 3), with the lowest frequency in those with symptoms only in childhood and intermediate levels (compared with controls) in those with persistent symptoms or onset in adulthood $\left(\chi^{2}\right.$ for trend 6.47, $\mathrm{p}=0.011$ ) When a history of smoking ever, atopy ever, CCR5 32 carrier status, and sex were entered into a logistic regression equation with "adult onset wheeze", "childhood only wheeze", and "persistent wheeze" as the dependant variables, smoking uptake appeared to be the predominant factor related to adult onset wheeze (OR 3.10, 95\% CI 2.03 to $4.74, \mathrm{p}=0.0001$ ) and history of atopy to the persistence of wheeze (OR $3.28,95 \%$ CI 1.93 to $5.56, p=0.0001$; table $4)$. As in the univariate analysis, the presence of the CCR5 $\Delta 32$ polymorphism was associated with a protective effect against childhood only wheeze (OR 0.23 , 95\% CI 0.08 to 0.66 , $\mathrm{p}=0.006)$.

\section{DISCUSSION}

Although 2082 individuals were traced, 675 addresses were unconfirmed and thus actual contact was established in 1407 cases with 627 individuals from this group completing full assessment. Depending on which denominator population is used, the response rate could be $30.2 \%$ or $44.6 \%$. The process of attrition is evident at all stages of the study, although we have tried to explain and describe characteristics of those lost where possible.

The 2082 individuals traced and those 1407 contacted were representative of the original 1989 whole population sample in terms of sex, social class, and symptoms (table 1 ). The sample of individuals $(n=711)$ who attended for more detailed

\begin{tabular}{|c|c|c|c|c|}
\hline $\begin{array}{l}\text { Wheezing } \\
\text { subgroup }\end{array}$ & CCR5 32 allelle & Atopy ever & Smoking ever & Female sex \\
\hline Adult onset & - & $\begin{array}{l}\text { OR } 1.99 \\
95 \% \mathrm{Cl} 1.3 \text { to } 3.05 \\
p=0.002\end{array}$ & $\begin{array}{l}\text { OR } 3.10 \\
95 \% \mathrm{Cl} 2.03 \text { to } 4.74 \\
p=0.0001\end{array}$ & - \\
\hline Childhood only & $\begin{array}{l}\text { OR } 0.23 \\
95 \% \mathrm{Cl} 0.08 \text { to } 0.66 \\
p=0.006\end{array}$ & $\begin{array}{l}\text { OR } 1.79 \\
95 \% \mathrm{Cl} 0.99 \text { to } 3.24 \\
\mathrm{p}=0.053\end{array}$ & - & $\begin{array}{l}\text { OR } 0.52 \\
95 \% \mathrm{Cl} 0.28 \text { to } 0.94 \\
p=0.03\end{array}$ \\
\hline Persistent & - & $\begin{array}{l}\text { OR } 3.28 \\
95 \% \mathrm{Cl} 1.93 \text { to } 5.56 \\
p=0.0001\end{array}$ & $\begin{array}{l}\text { OR } 2.18 \\
95 \% \mathrm{Cl} 1.34 \text { to } 3.54 \\
\mathrm{p}=0.001\end{array}$ & - \\
\hline
\end{tabular}


assessment had the same sex distribution as the 1989 cohort but comprised a greater proportion of symptomatic individuals whose families smoked less during childhood. There was also a trend (although not significant) towards a greater response from those in higher social classes. In 1989 the questionnaires were distributed through the schools and were therefore the responsibility of parents and teachers, whereas those attending in 1999/2000 were doing so voluntarily and, as might be anticipated, comprised a slight excess of symptomatic individuals who were only just beginning to take responsibility for their own health. The trends observed suggested that those with fewer symptoms were more likely to refuse to take part and fail to attend or reschedule appointments.

A further question arose regarding the different definitions of wheeze used in the two studies. In 1989 "wheeze within the last 3 years" constituted current wheeze. The standard definition has since changed to "wheeze within the last 12 months". In order to try and address this problem, we carried out a direct comparison of responses to the questions "wheeze within 3 years" and "within 12 months" in a different population of 908 schoolchildren of the same age as in the original 1989 survey. In this study the Aberdeen $^{23}$ and ISAAC ${ }^{24}$ questionnaires were directly compared by randomising children to receive one questionnaire first, followed by the other questionnaire a month later. Despite slight differences in the phraseology of the two questionnaires, and provided they were answered by the same parent on both occasions, there was a prevalence for wheeze in the past 3 years of $20.4 \%$ which was between the $14.1 \%$ prevalence of wheeze in the past 1 year and the $23.2 \%$ prevalence of ever wheeze. From the screening telephone questionnaire used at first contact in our study, in 1285 cases where these data were recorded we also found a difference of approximately 5\% between "wheeze in the last 3 years" (35.1\%) and "within the last 12 months" (29.9\%). Unfortunately this represents one of the many problems faced by studies carried out years apart-namely, the change in epidemiological tools. An adherence to original recording techniques would provoke questions regarding outdated methods, whereas any attempt to update them raises problems with comparison. No amount of foresight can predict these changes over time.

In the present cohort we found a similar carrier frequency for the CCR5 $\Delta 32$ mutation $(19.0 \%)$ to the $22.7 \%$ reported by Hall et $a l^{9}$ who examined a different sample drawn from the same north of Scotland population. This carrier rate is among the highest found in a white population but is consistent with the reported north/south European gradient. ${ }^{11}$

The results of our study confirm the protective effect of the CCR5 32 polymorphism on the expression of childhood asthma in the north of Scotland population. Although some of the numbers of individuals in the subgroups-based on the transition from child to adult-were small, our data would be consistent with different subtypes of childhood and adult asthma each with their different gene/environmental interactions. Active smoking was a clear risk factor for adult onset symptoms and atopy a clear risk factor for persistence, whereas the protective effect of carrying the CCR5 $\Delta 32$ polymorphism appeared to be confined to childhood. Moreover, the effect may only be significant in predominantly prepubertal children in whom the influences of atopic disease and adverse environmental exposures such as active smoking have not as yet made a significant contribution to persistence. ${ }^{25}$ Our suggestion that environmental factors other than modification of host response by CCR $5 \Delta 32$ effectively dilute this particular genetic contribution with advancing maturity would appear to be supported, at least in a population with a high expression of this particular polymorphism. Our observations also confirm the strength of both external (smoking uptake) and host factors (history of atopy) in influencing adult onset and persistence of childhood symptoms.
From studies examining the protective effects of the CCR5 $\Delta 32$ polymorphism in the acquisition of HIV, it appears that the mechanism of action is related to the inhibition of pathogen entry into cells and hence the disruption of the host response..$^{3-5}$ With the infection or "hygiene" hypothesis in mind, ${ }^{26}$ it has been suggested that any modification of the host response to common respiratory viruses should reduce the associated Thl driven responses, thus increasing the likelihood of atopic diseases including asthma. ${ }^{10}$ Although the infection hypothesis implies that Thl and Th2 diseases should be mutually exclusive, we have recently reported a positive association between Thl and Th2 modulated diseases in a large community sample. ${ }^{27}$ Furthermore, identification of individuals with wheezing illness from a community child population such as that studied here may have a different pathogenesis from populations recruited from hospital clinics and may have symptoms that are more related to respiratory viral infections and less associated with atopy. ${ }^{28}$ There is already strong evidence from long term follow up studies that virus associated wheeze—or what used to be labelled "wheezy bronchitis"-is more likely to resolve in the transition to adulthood. ${ }^{13}{ }^{14}$ We therefore suggest that any protective effect of the CCR5 332 polymorphism on wheezing illness in mid childhood would be consistent with what is known about the different wheezing syndromes in childhood and, in particular, the significant contribution of respiratory viral infections to childhood wheezing illness.

However plausible this particular candidate polymorphism is, it needs to be remembered that the area on the long arm of chromosome 3 also contains a number of other potential candidate genes that could be in linkage disequilibrium with CCR5 $\triangle 32$ and explain the association. Three other CCR genes (CCR1, CCR2, CCR3) are also clustered on human chromosome 3p21 where CCR5 is located, within about $400 \mathrm{~kb} .^{29}$ The results from this study do not therefore exclude the association between other CCR genes and asthma. Further work on identifying other potential candidates for the expression of childhood asthma within this region seems justified. In support of this observation, a case-control study in Hungarian children showed that the CCR5 $\Delta 32$ mutation does not confer a reduced risk to allergic inflammation in non-asthmatic children. ${ }^{30}$ Our failure to find any association with the expression of the atopic diseases (eczema and or rhinitis) either in childhood or in early adulthood further substantiates the irrelevance of CCR5 $\Delta 32$ to atopic disease. Finally, the hygiene hypothesis is largely focused on the Thl/Th2 switch whereas CCR5 is also expressed on dendritic cells, microglia and tissue macrophages, so a role for the dysfunctional mutation in protecting against asthma could also be argued for these cells.

It may be erroneous to assume that asthma across a wide range of ages, especially in the transition from childhood to adulthood, is caused by the same pathogenic process and this may explain the failure of replication in many reported association studies. The contribution of different candidate genes to different asthma phenotypes may therefore change with advancing maturity, and some such as CCR $5 \Delta 32$ may have little to do with atopy but may affect other processes involved in intermittent airway obstruction. We suggest that the CCR5 532 mutation, or another gene in the same area of chromosome 3, reduces the risk of asthma like symptoms in childhood but loses its effect in adulthood and has an influence that is independent of atopy. This changing genetic contribution may confound the interpretation of association and linkage studies.

\section{ACKNOWLEDGEMENTS}

The authors acknowledge D Shaw, S Rodgie, I Hall, G McNeill, $\mathrm{T}$ Ninan, and $\mathrm{H}$ Wassall for technical support and advice, and A Baird, S Bonner, A Mill, and L Adams for data collection. 


\section{Authors' affiliations}

P Srivastava, P J Helms, D Stewart, M Main, G Russell, Department of Child Health, University of Aberdeen, Aberdeen AB25 2ZD, UK

Financial support: Boehringer Ingelheim.

\section{REFERENCES}

1 Loetscher $\mathbf{P}$, Uguccioni M, Bordoli L, et al. CCR5 is characteristic of Th lymphocytes. Nature 1998;391:344-5.

2 Samson $M$, Libert F, Doranz BJ, et al. Resistance to HIV-1 infection in caucasian individuals bearing mutant alleles of the CCR-5 chemokine receptor gene. Nature 1996;382:722-5.

3 Dawson TC, Beck MA, Kuziel WA, et al. Contrasting effects of CCR5 and CCR2 deficiency in the pulmonary inflammatory response to influenza A virus. Am J Pathol 2000;156:1951-9.

4 Ianni A, Majore S, Arzani D, et al. CCR2 and CCR5 gene polymorphisms in children with recurrent respiratory infections. Respir Med 2001;95:430-2

5 Mangano A, Gonzalez E, Dhanda R, et al. Concordance between the $\mathrm{CC}$ chemokine receptor 5 genetic determinants that alter risks of transmission and disease progression in children exposed perinatally to human immunodeficiency virus. J Infect Dis 2001;183:1574-85.

6 Conti P, DiGioacchino M. MCP-1 and RANTES are mediators of acute and chronic inflammation. Allergy Asthma Proc 2001;22:133-7.

7 Tonnel AB, Gosset P, Tillie-Leblond I. Characteristics of the Inflammatory response in bronchial lavage fluids from patients with status asthmaticus. Int Arch Allergy Immunol 2001;124:267-71.

8 Blease K, Huffnage GB, Kuziel, et al. M. Prominent role for CCR5 and RANTES during chronic fungal asthma. Am J Respir Crit Care Med 2001; 163:A868.

9 Hall IP, Wheatley A, Christie G, et al. Association of CCR5 delta32 with reduced risk of asthma. Lancet 1999;354:1264-5

10 Mitchell TJ, Walley AJ, Pease JE, et al. Delta 32 deletion of CCR5 gene and association with asthma or atopy. Lancet 2000;356:1491-2.

11 Lucotte G, Mercier G. Distribution of the CCR5 gene 32-bp deletion in Europe. J Acquir Immune Defic Syndr Hum Retrovirol 1998;19:174-7.

12 lyer RK, Kim PS, Bando JM, et al. A multiethnic study of delta32ccr5 and ccr2b-V64l allele distribution in four Los Angeles populations. Diagn Mol Pathol 2001;10:105-10.
13 Godden DJ, Ross S, Abdalla M et al. Outcome of wheeze in childhood. Symptoms and pulmonary function 25 years later. Am J Respir Crit Care Med 1994;149:106-12.

14 Oswald H, Phelan PD, Lanigan A, et al. Outcome of childhood asthma in mid-adult life. BM 1994;309:95-6.

15 Roorda RJ. Prognostic factors for the outcome of childhood asthma in adolescence. Thorax 1996;51(Suppl 1):S7-12.

16 Ninan TK, Russell G. Respiratory symptoms and atopy in Aberdeen schoolchildren: evidence from two surveys 25 years apart. BM 1992;304:873-5.

17 Burr ML, Butland BK, King S, et al. Changes in asthma prevalence: two surveys 15 years apart. Arch Dis Child 1989;64:1452-6.

18 Robertson CF, Heycock E, Bishop J, et al. Prevalence of asthma in Melbourne schoolchildren: changes over 26 years. BM 1991;302:1116-8.

19 Burney PG, Luczynska C, Chinn S, et al. The European Community Respiratory Health Survey. Eur Respir J 1994;7:954-60.

20 Ferris BG. Epidemiology standardization project (American Thoracic Society). Am Rev Respir Dis 1978;1 18:1-120.

21 Cockcroft DW, Killian DN, Mellon JJ, et al. Bronchial reactivity to inhaled histamine: a method and clinical survey. Clin Allergy 1977;7:235-43.

22 Office of Population Census and Surveys. Classification of occupations. London: HMSO, 1980: 1-114

23 Dawson B, Horobin G, Illsley R, et al. A survey of childhood asthma in Aberdeen. Lancet 1969;i:827-30.

24 Asher MI, Keil U, Anderson HR, et al. Eur Respir J 1995:8:483-91.

25 Strachan D, Gerritsen J. Long-term outcome of early childhood wheezing: population data. Eur Respir J 1996;21:42-7s.

26 Strachan DP. Hay fever, hygiene, and household size. BM 1989;299:1259-60.

27 Simpson CR, Anderson WJA, Helms PJ, et al. Coincidence of immune mediated diseases driven by $\mathrm{TH} 1$ and $\mathrm{TH} 2$ subsets suggests a common aetiology. Clin Exp Allergy 2002;32:37-42.

28 Stevenson EC, Turner G, Heaney LG, et al. Bronchoalveolar lavage findings suggest two different forms of childhood asthma. Clin Exp Allergy 1997;27:1027-35.

29 Stephens JC, Reich DE, Goldstein DB, et al. Dating the origin of CCR5- $\Delta 32$ AIDS-resistance allele by coalescence of haplotypes. Am J Hum Genet 1998;62:1507-15.

30 Szalai C, Bojszko A, Beko G, et al. Prevalence of CCR5delta32 in allergic diseases. Lancet 2000;355:66.

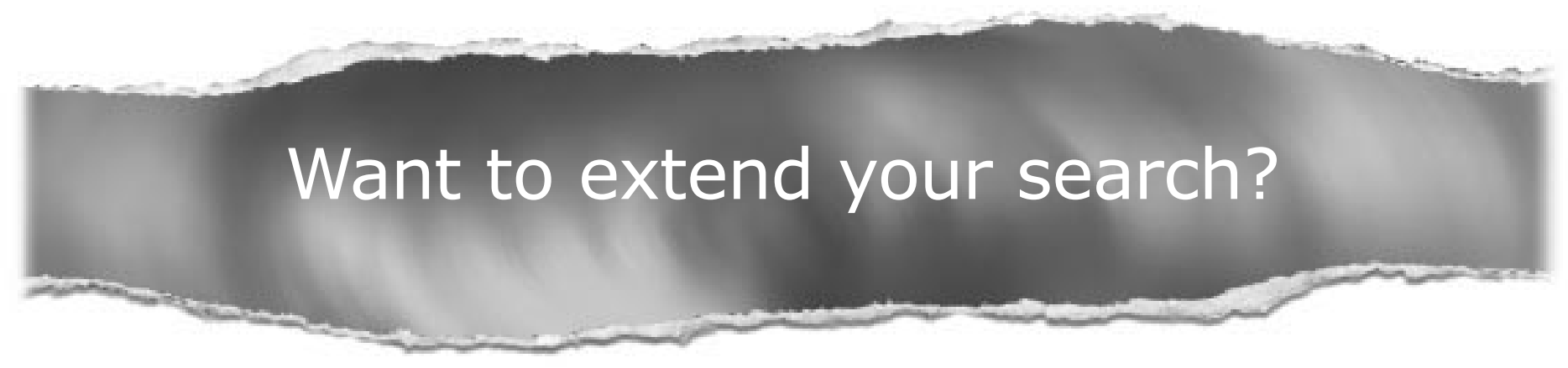

Cross journal searching

If you can't find what you are looking for in Thorax you can extend your search across many of the more than 200 journals available for selection. You can restrict your search to specific subject areas (eg, clinical medicine, basic research), or select specific journals, or search all available titles. 